\title{
UJI TAHANAN TARIK MODEL FONDASI TIANG DALAM TANAH PASIR
}

\author{
Andikanoza Pradiptiya ${ }^{1}$, Yuwono ${ }^{2}$ \\ Jurusan Teknik Sipil, Polteknik Negeri Jakata \\ e-mai:'andikanoza.pradiptiya@pnj.ac.id
}

\begin{abstract}
Certain buildings limit displacement of pile foundation with relatively small value so as not to cause damage to the structure. Loading test directly in the field requires a very high cost. To overcome this problem, it can be approached with a more economical cost, that is to move it into a certain scale models. The method used is to create a media model as a test box testing, by simulating the actual model in the form of a scale model. This method is fairly cheap and efficient as it can be used for various models and can be used repeatedly. The study was conducted using models of reduced scale single pile foundation made of concrete with a length of $0.2 \mathrm{~m}, 0.3 \mathrm{~m}, 0.4 \mathrm{~m}$ and each diameter of $0.02 \mathrm{~m}, 0.03 \mathrm{~m}, 0.04 \mathrm{~m}$. Pile model is jacked in clay soil that has been compacted in a box and then given a tensile load test referring to ASTM D3689-07 procedure $E$ (Constant Rate of Uplift Test). Mobilization of uplift resistance is determined from the pile frictional resistance force and displacement of the pile. The results showed that the frictional resistance value is reduced to the value at a particular displacement or at critical displacement pile.
\end{abstract}

Key words : uplift resistance, sand, mini pile.

\begin{abstract}
ABSTRAK
Beberapa konstruksi bangunan memberikan batasan kepada perpindahan tiang yang terjadi dengan nilai yang relatif kecil supaya tidak menyebabkan kerusakan struktur. Metode uji yang dipakai adalah membuat box uji model sebagai media pengujian, dengan mensimulasikan model yang sebenarnya ke dalam bentuk model skala. Penelitian dilakukan menggunakan model fondasi tiang tunggal skala tereduksi yang terbuat dari beton dengan panjang 0,2 m, 0,3 m, 0,4 $\mathrm{m}$ dan masing-masing diameter 0,02 m, 0,03 m, 0,04 m. Model tiang dipasang dengan cara ditekan pada tanah pasir yang sudah dipadatkan dalam box uji kemudian diberikan beban tarik yang mengacu pada ASTM D3689-07 prosedur E (Constant Rate of Uplift Test). Tahanan tarik tiang ditentukan tahanan gesek satuan dan perpindahan tiang berdasarkan variasi pengaruh diameter dan panjang tiang. Hasil penelitian menunjukkan bahwa nilai tahanan gesek satuan ultimit (fs) dan perpindahan kritis $(\delta c)$ relatif menurun dengan bertambahnya ukuran diameter (d) tiang tetapi sebaliknya nilai fs tiang meningkat dengan dengan bertambahnya ukuran panjang $(L)$ tiang. Semakin besar panjang tiang memperlihatkan kecenderungan bahwa pengaruh tekanan tanah lateral pasir terhadap selimut tiang meningkat sehingga memberikan kontribusi tahanan gesek yang lebih besar, sedangkan penambahan diameter tiang tidak meningkatkan tekanan tanah lateral pasir terhadap tiang.
\end{abstract}

Katakunci : Tahanan tarik, pasir, Model Fondasi tiang.

\section{PENDAHULUAN}

Setiap tanah merupakan material yang unik dan memiliki karakteristik yang kompleks. Semua struktur bangunan bertumpu pada kekuatan tanah yang mendukungnya sehingga di dalam merencanakan suatu struktur bangunan haruslah benar-benar memahami tentang jenis dan karakteristik tanah secara detail. Beberapa konstruksi bangunan memberikan batasan kepada perpindahan tiang yang terjadi dengan nilai yang relatif kecil supaya tidak menyebabkan kerusakan struktur. Hingga saat ini masih banyak fenomena kerusakan/kegagalan

struktur bangunan yang masih sulit diprediksi, antara lain kegagalan fondasi, bangunan miring, tanah longsor maupun jalan amblas. Hal ini diakibatkan oleh kurangnya data dan pemahaman terhadap jenis maupun karakter dari suatu tanah yang mendukung bangunan tersebut. Untuk mendapatkan data dari suatu tanah seperti indeks property maupun engeneering 
propertys dapat dilalakukan di laboratorium, sedangkan untuk mengetahui perilaku struktur yang sebenarnya terhadap pembebanan maka haruslah dilakukan uji coba di lapangan. Pengujuian secara langsung di lapangan memerlukan biaya yang sangat tinggi. Untuk mengatasi kondisi ini maka perlu dibuatkan media lapangan yang dapat dipindahkan ke laboratorium dengan menggunakan model fondasi tiang dengan skala tertentu. 'Box uji model' ini bersifat portable yang di dalamnya dilengkapi dengan ruang media tanah, penempatan model struktur, peralatan pembebanan, angkur serta alat alat ukur lainnya. Pada 'box uji model' dapat dipergunakan untuk mengamati berbagai model struktur bangunan bawah misalnya : model fondasi dangkal maupun fondasi dalam, fondasi perkerasan jalan serta berbagai struktur bangunan bawah. Proses pemakaian 'box uji model' dapat disimulasikan dari kondisi tanah yang ada dilapangan hingga model strukur yang dibuat, selanjutnya dapat dilakukan loading test pada berbagai model struktur yang diamati tersebut. Dari hasil pengujian dengan skala model ini diharapkan dapat memperoleh data respon struktur yang lebih dekat dengan kondisi di lapangan yang sebenarnya, serta biaya yang lebih murah.

\section{Pondasi Tiang Tarik}

Pembebanan tarik pada fondasi tiang ditahan dengan mengerahkan tahanan gesek tiang ditambah dengan berat tiang sendiri dan bisa juga dengan memperbesar ujung tiang. Fondasi tiang yang menahan beban tarik di antaranya adalah fondasi tiang pada bangunan-bangunan tingkat tinggi yang dipengaruhi oleh gaya penggulingan akibat beban angin dan fondasi tiang pada sistem pelat terpaku (nailed slab) yang mengalami gaya tarik akibat penurunan tanah yang tidak seragam. Pengamatan Bose dk. (2009) memperlihatkan bahwa untuk pengujian tarik model tiang pada tanah pasir, tahanan yang dikerahkan tiang terhadap pergerakan axial akan bertambah dengan pertambahan perbandingan panjang dan diameter tiang (L/d). Penelitian Rihardjo (2006) di antaranya mengamati perilaku tiang tunggal ketika diberi beban tarik axial sentris pada tanah pasir dan menunjukkan bahwa semakin panjang tiang akan semakin besar kapasitas tarik ultimitnya. Bowles (1994) memberikan gambaran terhadap fondasi tiang yang menahan beban tarik seperti pada Gambar. 1

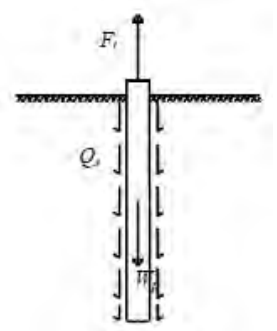

Gambar. 1 Pondasi tiang menahan beban tarik (Bowles, 1994)

Gaya tarik $\left(\mathrm{F}_{\mathrm{t}}\right)$ yang bekerja pada kepala tiang dalam Gambar. 1 menunjukkan akan dilawan oleh tahanan gesek tiang $\left(\mathrm{Q}_{\mathrm{s}}\right)$ dan berat sendiri tiang $\left(\mathrm{W}_{\mathrm{p}}\right)$.

\section{Perpindahan kritis tahanan gesek tiang}

Perpindahan kritis $\left(\delta_{c}\right)$ tiang adalah perpindahan tiang pada saat tahanan gesek sudah termobilisasi sepenuhnya atau sudah mencapai kondisi ultimit. Srivastava dkk. (2008) mencantumkan beberapa nilai perpindahan axial kritis tiang $\left(\delta_{c}\right)$ yang disarankan untuk tiang yang mengalami gaya tarik seperti yang diperlihatkan pada Tabel.1.

Tabel.1. Nilai $\delta_{c}$ pada tiang pembebanan tarik

\begin{tabular}{|c|c|c|}
\hline $\begin{array}{c}\text { Perpindahan } \\
\text { tiang }\end{array}$ & $\begin{array}{c}\text { Kondisional tiang- } \\
\text { tanah }\end{array}$ & Referensi \\
\hline $\begin{array}{c}5-6,25 \\
\text { mm }\end{array}$ & $\begin{array}{c}\text { Tiang baja pancang } \\
\text { di tanah pasir }\end{array}$ & $\begin{array}{c}\text { Mcelland } \\
(1974)\end{array}$ \\
\hline $\begin{array}{c}6,25-12,5 \\
\text { mm }\end{array}$ & $\begin{array}{c}\text { Tiang bor di tanah } \\
\text { pasir }\end{array}$ & $\begin{array}{c}\text { Ismael dan } \\
\text { Klym } \\
(1979)\end{array}$ \\
\hline $\begin{array}{c}0,5 \%-0,1 \\
\% \text { dari } \\
\text { diameter } \\
\text { tiang }\end{array}$ & $\begin{array}{c}\text { Tiang di tanah pasir } \\
\text { dan lempung }\end{array}$ & $\begin{array}{c}\text { Tomlinson } \\
(1987)\end{array}$ \\
\hline $5-10 \mathrm{~mm}$ & $\begin{array}{c}\text { Tiang bor ditanah } \\
\text { pasir dan lempung }\end{array}$ & $\begin{array}{c}\text { Kulhawy } \\
(1985)\end{array}$ \\
\hline \hline
\end{tabular}


Tahanan gesek termobilisasi fondasi tiang Vijayvergiya (1977) dalam Mosher dkk. (2000) mengusulkan bahwa tahanan gesek satuan yang termobilisasi adalah fungsi dari perpindahan (displacement) tiang yang terjadi seperti yang ditunjukkan pada Gambar.2.

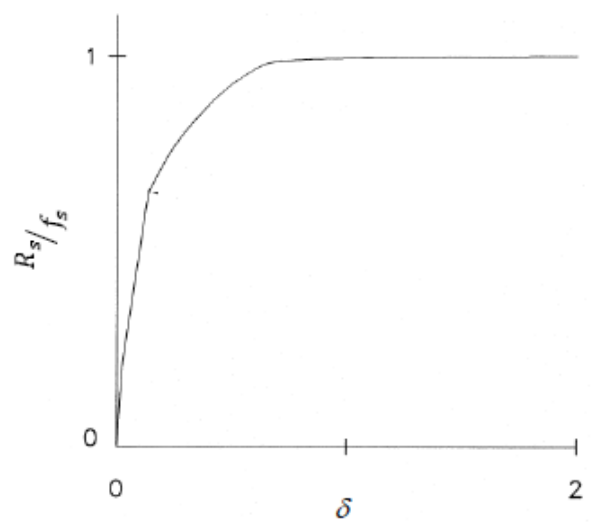

Gambar 2. Grafik hubungan tahanan gesek satuan termobilisasi pada perpindahan tiang (Vijayvergiya,1977 dalam Mosher dkk., 2000)

Persamaan tahanan gesek satuan termobilisasi terhadap perpindahan yang diusulkan oleh Vijayvergiya (1977) dalam Mosher dkk. (2000) adalah :

$R_{s}=f_{s}\left\{2 \sqrt{\frac{\delta}{\delta_{c}}}-\frac{\delta}{\delta_{c}}\right\}$

(1)

$$
R_{s}=2 f_{s} \sqrt{\frac{\delta}{\delta_{c}}}-\left\{\frac{f_{s}}{\delta_{c}} \delta\right\}
$$

$$
k_{t}=\frac{f_{s}}{\delta_{c}}
$$

$$
R_{s}=2 f_{s} \sqrt{\frac{\delta}{\delta_{c}}}-k_{t} \delta
$$

dengan

$R_{S}=$ tahanan gesek satuan termobilisasi $\left(\mathrm{kN} / \mathrm{m}^{2}\right)$

$f_{s}=$ tahanan gesek satuan maksimum atau ultimit $\left(\mathrm{kN} / \mathrm{m}^{2}\right)$

$\delta_{c}=$ perpindahan (displacement) tiang pada saat tahanan gesek satuan termobilisasi sepenuhnya $\left(f_{s}\right)(\mathrm{m})$ $k_{t}=$ modulus gesek saat tahanan gesek satuan termobilisasi sepenuhnya $\left(\mathrm{kN} / \mathrm{m}^{3}\right)$

$\delta=$ perpindahan (displacement) tiang yang terjadi (m)

Mosher dkk. (2000) menyatakan bahwa hubungan tersebut dapat digunakan untuk tiang tarik pada tanah pasir dan lempung. Mosher dkk. (2000) juga menyarankan agar nilai $f_{s}$ yang digunakan pada tanah pasir direduksi sebesar $70 \%$, sedangkan tiang pada tanah lempung $f_{s}$ tidak direduksi.

Vijayvergiya (1970) dalam Mosher dkk. (2000) memberikan batasan nilai tahanan gesek satuan maksimum $\left(f_{s}\right)$ sebesar 1 tsf $\left(105,6 \mathrm{kN} / \mathrm{m}^{2}\right)$ untuk tiang pada tanah pasir bersih kondisi padat, 0,85 tsf $\left(89,76 \mathrm{kN} / \mathrm{m}^{2}\right)$ untuk tiang pada tanah pasir kelanauan, 0,7 tsf $\left(73,92 \mathrm{kN} / \mathrm{m}^{2}\right)$ untuk tiang pada tanah lanau kepasiran dan 0,5 tsf $\left(52,8 \mathrm{kN} / \mathrm{m}^{2}\right)$ untuk tiang pada tanah lanau.

\section{METODE PENELITIAN Prosedur pembuatan box uji model}

Pembuatan box uji meliputi dari tahapan awal persiapan, tahapan pembuatan kerangka dan dinding serta dilanjutkan dengan tahapan finishing yang dilengkapi dengan alat ukur gaya dan pergerakan.

\section{Tahapan persiapan}

Pada tahap persiapan ini mulai menghitung kebutuhan bahan dan alat yang akan dipergunakan. Kebutuhan bahan dan alat yang diperlukan ditabelkan sehingga penyediaan bahan dan alat dapat dilakukan sesuai kebutuhan. Kemudian dilanjutkan dengan pemotongan bahan sesuai dengan ukuran dan jumlah yang dibutuhkan untuk pembuatan model. Dalam pemotongan diupayakan agar penggunaan bahan seefisien mungkin dengan menghindari kesalahan ukuran maupun jumlah dalam pemotongan. Hal ini dapat dilakukan dengan pembuatan tabel ukuran pemotongan dan jumlah potongan bahan yang diperlukan. Pada kondisi ini dapat dievaluasi tentang jumlah dan jenis bahan 
yang diperlukan, apabila masih terdapat kekurangan bahan maka masih bisa dipenuhi.

\section{Tahapan perakitan.}

Perakitan penyambungan kerangka box uji dengan menggunakan system las listrik. Penyempurnaan kerangka box uji dengan pengukuran kesikuan sudut-sudut pertemuan kerangka serta memperbaikinya apabila terdapat kekurangan. Setelah pembuatan kerangka telah selesai maka dapat dilakukan pemasangan dindingdinding samping dari bahan multiplek, serta alas lantai box uji dari bahan plat baja. Selanjutnya dilakukan pembuatan angkur dari bahan baja berbentuk holo (pipa kotak berlubang). Angkur yang terbuat dari kerangka baja ini berfungsi sebagai penempatan alat-alat ukur apabila dikemudian hari box uji ini dipergunakan. Pada tahap terakhir adalah pekerjaan finishing yang berupa pengecatan kerangka maupun dinding box uji serta pemasangan asesoris lainnya. Dalam pengoperasiannya box uji ini dilengkapi dengan proving ring untuk mengukur gaya dan dial gauge dipakai untuk mengukur pergerakan

dengan ketelitian tertentu.

\section{Bahan}

Bahan-bahan yang digunakan dalam pembuatan box uji model.

\section{Besi Kerangka}

Besi yang digunakan sebagai kerangka untuk pembuatan kotak uji (box uji model) harus kuat menahan beban lateral maupun vertical dari tanah di dalam box uji model tanpa mengalami lendutan yang berlebihan, sehingga dipilih baja profil ukuran L 60.60.6. Sedangkan untuk angkur terdiri dari tiga bagian yaitu :

a. Kerangka baja kotak system Cremona

b. Dua pasang Tiang angkur kedudukan kerangka.

c. Kait tiang angkur yang diletakan pada dasar box untuk mengikat tiang angkur agar tidak bergerak. Untuk kebutuhan angkur ini dipilih dari batang baja kotak ukuran 60x40x4 cm.

\section{Multiplek \& plat bordes}

Dinding box uji model dibuat dari multiplex tebal $18 \mathrm{~mm}$ dan dilapisi dengan cat yang tidak tembus air maupun lembaran plastik. Sedang plat bordes dipergunakan sebagai lantai.

\section{Alat penguat}

Alat penguat sambungan dilakukan dengan system las listrik. Sedang alat pengikat lainnya digunakan mur-baut, paku, dan lem untuk memperkuat box uji model.Alat ukur, berupa alat ukur gaya (proving ring) dan dial gauge. Model tiang dibuat dari campuran material pasir halus dan semen dengan bentuk selinder berupa tiang tunggal. Pasir yang digunakan adalah pasir halus dengan ukuran sekitar $0,15 \mathrm{~mm}$ atau lolos saringan nomor 100 agar memperoleh kekasaran sisi tiang yang relatif sama. Campuran semen dan pasir adalah 1 berbanding 2, dengan air yang diatur sehingga campuran mudah dicetak. Tulangan dirangkai dari kawat ukuran 2 $\mathrm{mm}$. Spesifikasi model fondasi tiang bervariasi dengan diameter $0,04 \mathrm{~m}, 0,03 \mathrm{~m}$, $0,02 \mathrm{~m}$ dan panjang $0,4 \mathrm{~m}, 0,3 \mathrm{~m}, 0,2 \mathrm{~m}$. Kepala tiang diberikan sebuah lempengan tipis sebagai tempat meletakkan dial gauge untuk pengukuran perpindahan tiang yang terjadi. Model tiang uji dapat dilihat seperti pada Gambar. 3.

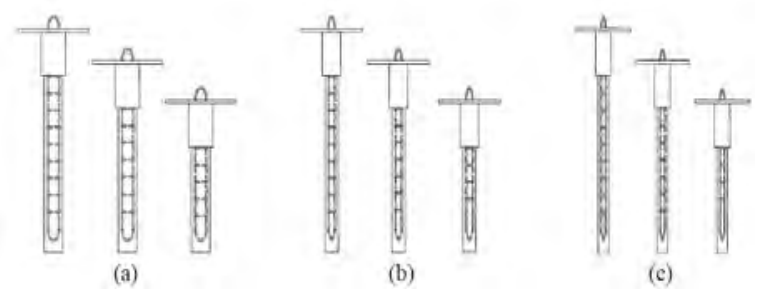

Gambar 3. Model fondasi tiang

a. Diameter 0,04 $\mathrm{m}$ dengan panjang 0,4 $\mathrm{m}$, $0,3 \mathrm{~m}, 0,2 \mathrm{~m}$.

b. Diameter $0,03 \mathrm{~m}$ dengan panjang $0,4 \mathrm{~m}$, $0,3 \mathrm{~m}, 0,2 \mathrm{~m}$.

c. Diameter 0,02 $\mathrm{m}$ dengan panjang 0,4 m, 


$$
\text { 0,3 m, 0,2 m. }
$$

\section{Alat}

Pealatan yang diperlukan untuk pembuatan box uji model.

Alat mesin:

Alat pemotong besi, alat pemotong dan pembelah kayu. Bor tangan/mesin.1 unit alat las listrik.Mesin gerinda.

\section{Alat tangan:}

Waterpas, roll meter, penggores, siku-siku. Kunci pas/ring, obeng, palu, 1 unit alat pengecatan, dan lain lain.

\section{Gambar rancangan box uji model}

Box uji yang telah dilengkapi dengan media tanah yang diteliti, kerangka angkur,beberapa model dan alat pengukur gaya serta dial gauge untuk mengukur displacement seperti pada Gambar 4.

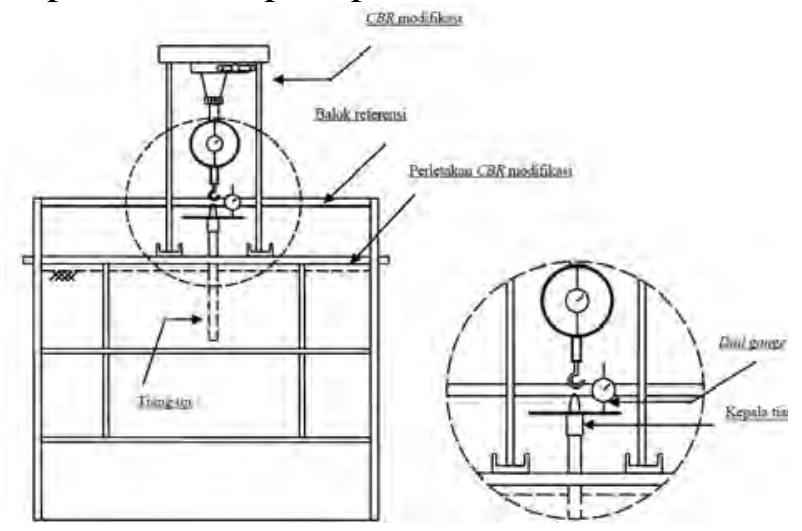

Gambar 4. Box Uji

\section{HASIL DAN PEMBAHASAN}

\section{Hasil Uji Tarik Model Tiang}

Hasil uji beban tarik seluruh tiang pada tanah pasir untuk setiap perpindahan axial tiang diperlihatkan pada Gambar 5. Pembebanan dilakukan sampai tidak ada lagi peningkatan atau pertambahan beban yang terbaca pada perpindahan tertentu.

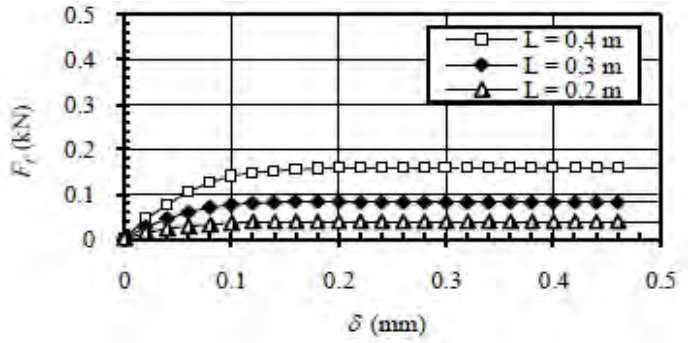

(a)

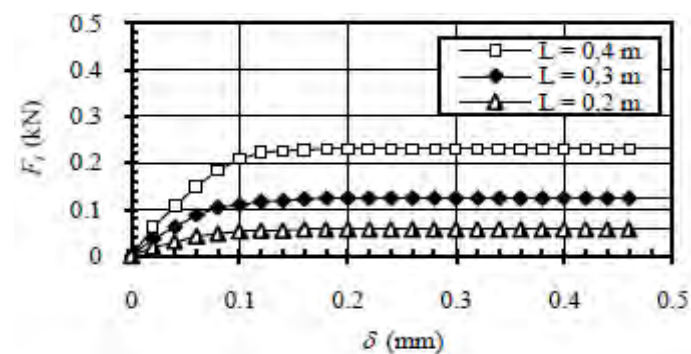

(b)

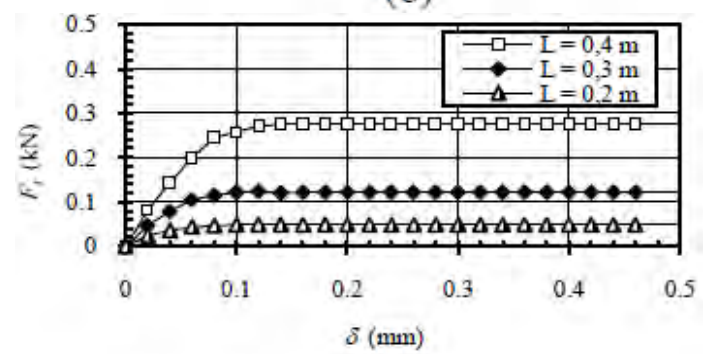

(c)

Gambar 5. Hubungan $F_{t}$ dan $\delta$ tiang pada tanah pasir
a.Tiang $d=0,02 \mathrm{~m}$.
b.Tiang $d=0,03 \mathrm{~m}$.
c.Tiang $d=0,04 \mathrm{~m}$.

Pembebanan masih dilakukan pada perpindahan tiang yang lebih besar dalam Gambar 5 karena kondisi keruntuhan tiang pada tanah pasir memperlihatkan kecenderungan terjadinya beban yang relatif konstan pada pertambahan perpindahan tiang. Nilai tahanan tarik ultimit hasil uji tiang pada tanah pasir dalam Gambar 5 menunjukkan akan tercapai pada perpindahan tiang (displacement) sekitar $0,08 \mathrm{~mm}$ sampai dengan $0,18 \mathrm{~mm}$.

Rangkuman nilai tahanan tarik pada saat mencapai kondisi ultimit $\left(Q_{t}\right)$ untuk seluruh tiang uji dalam Gambar 5 dicantumkan dalam Tabel 2 
Tabel 2. Nilai $Q_{t}$ tiang pada tanah pasir

\begin{tabular}{|c|c|c|c|c|c|c|c|}
\hline No & $\begin{array}{c}d \\
(\mathrm{~m})\end{array}$ & $\begin{array}{c}L \\
(\mathrm{~m})\end{array}$ & $\begin{array}{c}Q_{t} \\
(\mathrm{kN})\end{array}$ & No & $\begin{array}{c}d \\
(\mathrm{~m})\end{array}$ & $\begin{array}{c}L \\
(\mathrm{~m})\end{array}$ & $\begin{array}{c}Q_{t} \\
(\mathrm{kN})\end{array}$ \\
\hline \hline 1 & 0,04 & 0,2 & 0,046 & 6 & 0,03 & 0,4 & 0,226 \\
\hline 2 & 0,04 & 0,3 & 0,122 & 7 & 0,02 & 0,2 & 0,036 \\
\hline 3 & 0,04 & 0,4 & 0,270 & 8 & 0,02 & 0,3 & 0,084 \\
\hline 4 & 0,03 & 0,2 & 0,048 & 9 & 0,02 & 0,4 & 0,156 \\
\hline 5 & 0,03 & 0,3 & 0,116 & - & - & - & - \\
\hline
\end{tabular}

\section{Tahanan gesek satuan termobilisasi}

Hubungan tahanan gesek satuan termobilisasi $\left(R_{S}\right)$ pada setiap perpindahan $(\delta)$ tiang tertentu dari hasil uji beban tarik tiang pada tanah pasir diperlihatkan seperti pada Gambar 6. Tahanan gesek ultimit satuan $\left(f_{s}\right)$ diperoleh dari nilai tahanan gesek satuan $\left(R_{S}\right)$ yang termobilisasi sepenuhnya pada perpindahan tiang kritis $\left(\delta_{c}\right)$.

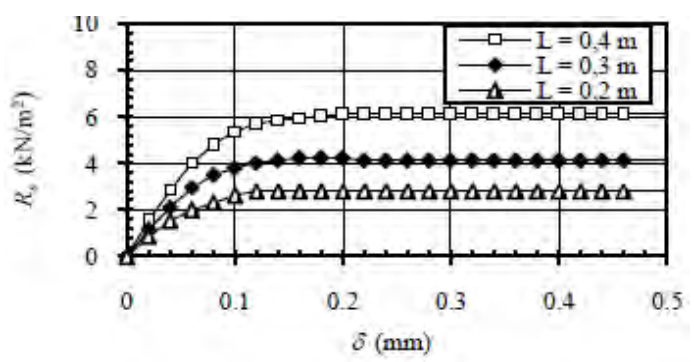

(a)

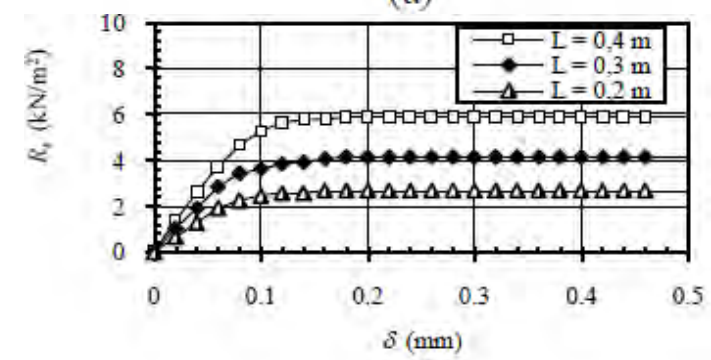

(b)

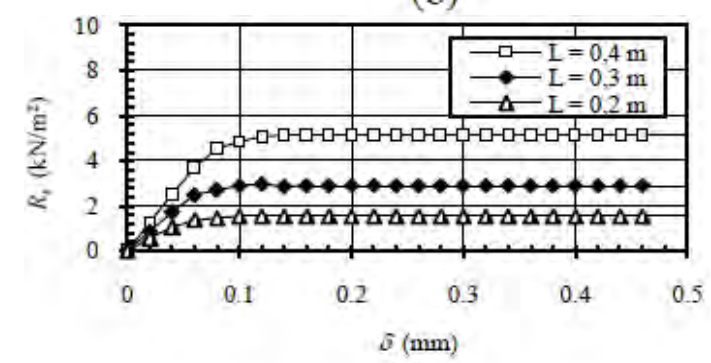

(c)

Gambar 6 Hubungan $R_{s}$ dan $\delta$ tiang pada tanah pasir

a.Tiang $d=0,02 \mathrm{~m}$.

b.Tiang $d=0,03 \mathrm{~m}$. c. Tiang $d=0,04 \mathrm{~m}$.

Tahanan gesek satuan termobilisasi $\left(R_{S}\right)$ hasil uji tiang pada tanah pasir dalam Gambar 6 menunjukkan kurva dengan hubungan yang relatif sebanding terhadap pertambahan perpindahan tiang antara 0,02 $\mathrm{mm}$ sampai $0,06 \mathrm{~mm}$. Rangkuman nilai $f_{s}$ dan $\delta_{c}$ seluruh tiang uji dalam Gambar 6 dicantumkan dalam Tabel 3.

Tabel 3. Nilai $f_{s}$ dan $\delta_{c}$ tiang pada tanah pasir

\begin{tabular}{|c|c|c|c|c|c|}
\hline No & $\begin{array}{c}d \\
(\mathrm{~m})\end{array}$ & $\begin{array}{c}L \\
(\mathrm{~m})\end{array}$ & $\begin{array}{c}\delta_{c} \\
(\mathrm{~mm})\end{array}$ & $\begin{array}{c}f_{s} \\
\left(\mathrm{kN} / \mathrm{m}^{2}\right)\end{array}$ & $\begin{array}{c}\delta_{c} / d \\
(\%)\end{array}$ \\
\hline 1 & 0,04 & 0,2 & 0,08 & 1,45 & 0,20 \\
\hline 2 & 0,04 & 0,3 & 0,10 & 2,90 & 0,25 \\
\hline 3 & 0,04 & 0,4 & 0,12 & 5,07 & 0,30 \\
\hline 4 & 0,03 & 0,2 & 0,08 & 2,26 & 0,27 \\
\hline 5 & 0,03 & 0,3 & 0,12 & 3,86 & 0,40 \\
\hline 6 & 0,03 & 0,4 & 0,14 & 5,77 & 0,47 \\
\hline 7 & 0,02 & 0,2 & 0,10 & 2,64 & 0,50 \\
\hline 8 & 0,02 & 0,3 & 0,16 & 4,24 & 0,80 \\
\hline 9 & 0,02 & 0,4 & 0,18 & 6,01 & 0,90 \\
\hline
\end{tabular}

Nilai rasio $\delta_{c}$ dan diameter $\delta_{c} / d$ masingmasing tiang uji dalam Tabel 3 adalah sekitar 0,20\% sampai 0,90\%.

Grafik pengaruh panjang dan diameter tiang terhadap tahanan gesek satuan termobilisasi dapat dilihat sperti pada Gambar 7 dan Gambar 8.

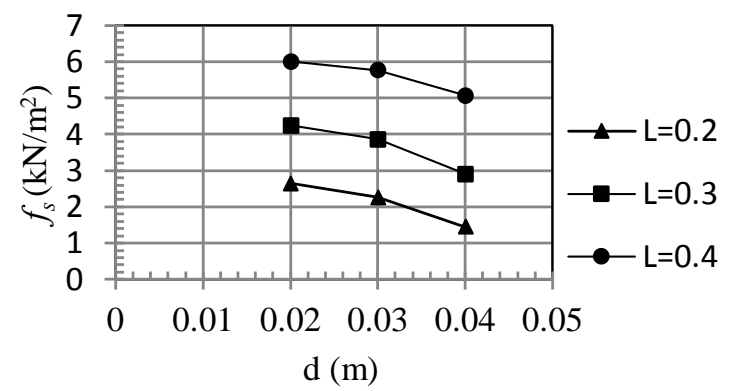

Gambar 7. Pengaruh diameter (d) tiang terhadap tahanan gesek satuan ultimit $\left(f_{s}\right)$

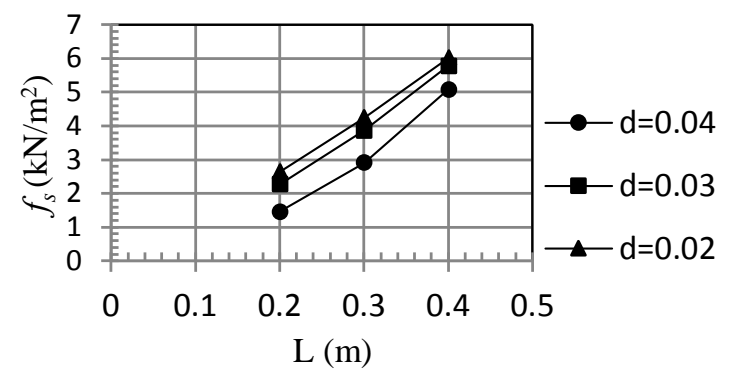


Gambar 7. Pengaruh panjang (L) tiang terhadap tahanan gesek satuan ultimit $\left(f_{s}\right)$

Perpindahan tiang kritis $\left(\delta_{c}\right)$ hasil uji berdasarkan pengaruh panjang tiang $(L)$ dari tiang dengan diameter masing-masing $0,02 \mathrm{~m}, 0,03 \mathrm{~m}, 0,04 \mathrm{~m}$ dapat dilihat seperti pada Gambar 8.

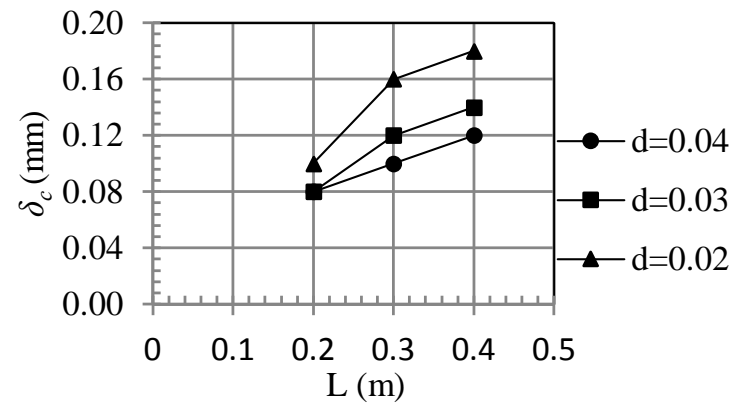

Gambar 9 Hubungan $\delta_{s}$ dan $L$ tiang pada tanah pasir

Perpindahan tiang kritis $\left(\delta_{c}\right)$ hasil uji berdasarkan pengaruh diameter tiang $(d)$ dari tiang dengan diameter masing-masing 0,02 m, 0,03 m, 0,04 m dapat dilihat seperti pada Gambar 10

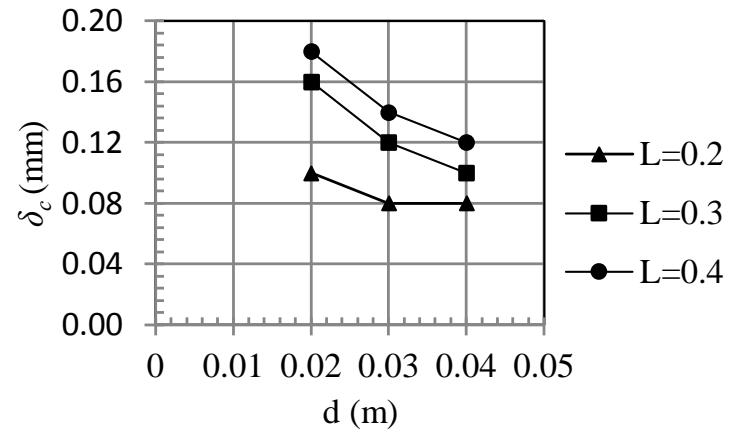

Gambar 10. Hubungan $\delta_{c}$ dan d tiang pada tanah pasir

\section{KESIMPULAN}

1. Pertambahan besaran diameter $(d)$ dan panjang $(L)$ tiang sesuai dengan peningkatan nilai tahanan tarik total $\left(Q_{t}\right)$ tiang

2. Nilai tahanan gesek satuan ultimit $\left(f_{s}\right)$ dan perpindahan kritis $\left(\delta_{c}\right)$ relatif menurun dengan bertambahnya ukuran diameter $(d)$ tiang tetapi sebaliknya nilai $f_{s}$ tiang meningkat dengan dengan bertambahnya ukuran panjang $(L)$ tiang.

3. Semakin besar panjang tiang memperlihatkan kecenderungan bahwa pengaruh tekanan tanah lateral pasir terhadap selimut tiang meningkat sehingga memberikan kontribusi tahanan gesek yang lebih besar, sedangkan penambahan diameter tiang tidak meningkatkan tekanan tanah lateral pasir terhadap tiang.

\section{DAFTAR PUSTAKA}

[1] Hardiyatmo, H. (2011). Method to Analyze The Deflection of The Nailed Slab. International Journal of Civil \& Environmental Engineering, 22-28.

[2] Mosher, R., \& Dawkins, W. (2000). Theoretical Manual of Piles Foundation. Washington, DC: US Army Corps of Engineers.

[3] Omer, J., Delpak, R., \& Robinson, R. (2010). An Empirical Method for Analysis of Load Transfer and Settlement of Single Piles. Springer Science Business Media B.V , 483501. 
Andikanoza Pradiptiya dan Yuwono, Uji Tahanan Tarik... 